\title{
EDITORIAL
}

\section{Ein Jahrzehnt Pädiatrisch-Onkologische Therapiestudien in der Bundesrepublik Deutschland}

\section{F. Lampert}

Was vor über einem Jahrzehnt mit der Einführung der Hirnschädelbestrahlung und einer einfachen, aber doch schon wirkungsvollen Kombinationschemotherapie „lose" bei Kindern mit akuter lymphoblastischer Leukämie begann - entsprechend dem Konzept, jedes neu erkrankte Kind seiner malignen Krankheit gemäß einheitlich prospektiv nach festgelegten Studienplänen zu behandeln und auszuwerten ist nun zu einer etablierten Gewohnheit geworden. Inzwischen sind auf dem Boden einer sehr disziplinierten und effektiven Kooperation neue Protokolle mit einer viel intensiveren Therapie entstanden. Einen Überblick über die Ergebnisse der größeren Therapiestudien gibt Tabelle 1.

Nur durch die so verfügbare große Patientenzahl können gesicherte Ergebnisse und therapeutische Erfahrungen in relativ kurzer Zeit erzielt werden, die auch international Anerkennung finden können.

Innerhalb dieses Jahrzehnts hat jeder einzelne pädiatrische Onkologe - an Stadt- oder Universitäts-Kinderklinik, ,im sicheren Boot mitfahrend", d.h. unterstützt von den jewei- ligen Studienleitungen - nicht nur sehr viel geleistet, sondern auch sehr viel dabei gelernt. In dieser Richtung sollten wir mit Konsequenz weitergehen und damit zu einer Effektivität kommen, die letztlich jedem Kind zugute kommt.

Zwar ist die Tumortherapie noch nicht optimal und müßte noch weiter verfeinert werden, aber sie ist ,im Griff" und mit Ausnahme des disseminierten Neuroblastoms auch größtenteils kurativ.

Jetzt sollten jedoch auch Fortschritte in der Pathogenese und Âtiologie der Tumoren erzielt werden, z.B. mit Hilfe der aufgebauten Organisation und Kooperation. Die vielfältigsten Gewebeuntersuchungen durch verschiedene Methoden in den darauf spezialisierten Labors könnten im Rahmen eines identisch behandelten Kollektivs durchgeführt werden. Nach der Tumortherapie könnte so vielleicht die Pädiatrie auch auf dem Gebiet der Tumorgenese wegweisend sein.

Tab. 1 Ergebnisse pädiatrisch-onkologischer Behandlungsstudien in der Bundesrepublik Deutschland

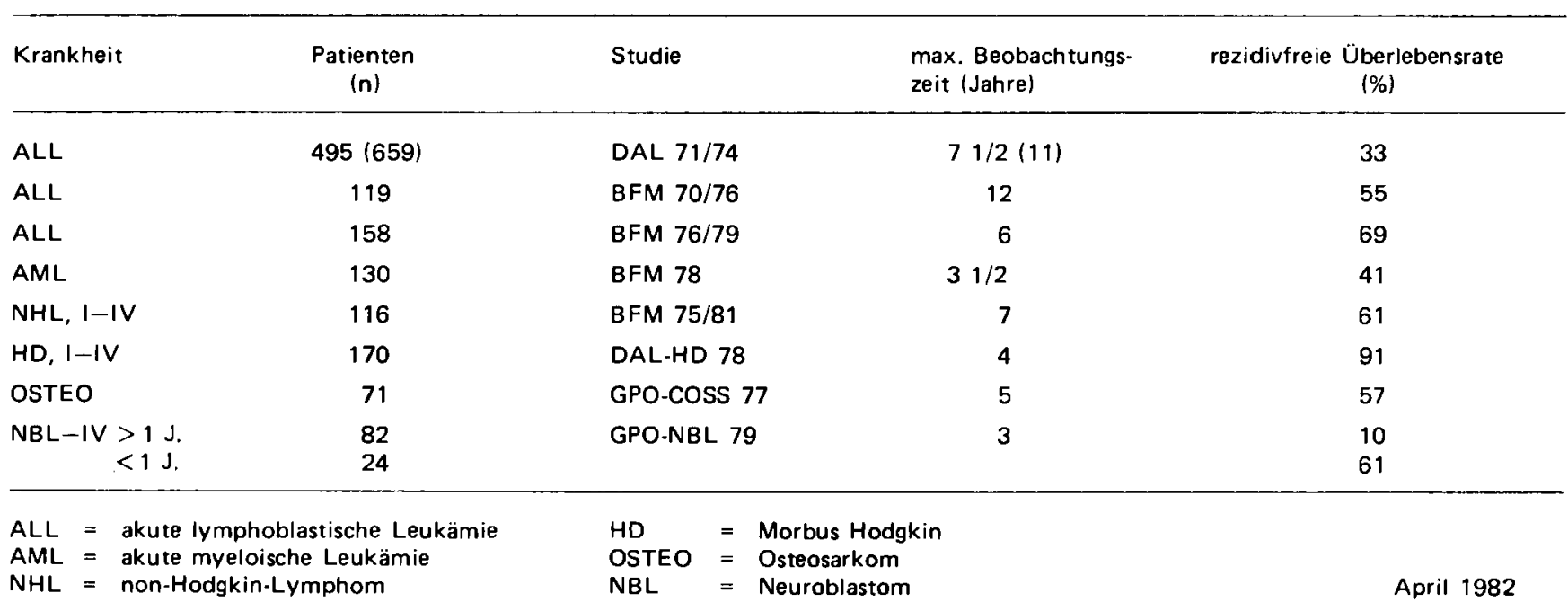

Prof. Dr. F. Lampert, Universitöts-Kinderpoliklinik, Feulgenstraße 12, 6300 Gießen 